NBER WORKING PAPER SERIES

\title{
THE BENEFITS OF REDUCING \\ GUN VIOLENCE: EVIDENCE FROM \\ CONTINGENT-VALUATION SURVEY DATA
}

Jens Ludwig

Philip J. Cook

Working Paper 7166

http://www.nber.org/papers/w7166

\author{
NATIONAL BUREAU OF ECONOMIC RESEARCH \\ 1050 Massachusetts Avenue \\ Cambridge, MA 02138 \\ June 1999
}

This paper was supported by a grant from the Joyce Foundation and written in part while the first author was visiting scholar to the Northwestern University / University of Chicago Joint Center for Poverty Research. We are indebted to the Johns Hopkins Center for Gun Policy and Research and NORC for the opportunity to make use of their annual gun survey. Thanks to Mark Cohen, Ted Gayer, Arlene Greenspan, Jay Hamilton, Steve Hargarten, David Hemenway, Joel Huber, Arthur Kellermann, Debby Leff, Will Manning, Ted Miller, John Mullahy, Terry Richmond, Seth Sanders, Bill Schwab, Kurt Schwabe, Kerry Smith, Daniel Webster, and seminar participants at the 1998 ASC and 1999 AEA meetings for helpful comments. Thanks to Bruce Lawrence and Bob Malme for help with the calculations. Any errors of fact or interpretation are those of the authors. All opinions expressed are those of the authors and not those of the National Bureau of Economic Research.

(C) 1999 by Jens Ludwig and Philip J. Cook. All rights reserved. Short sections of text, not to exceed two paragraphs, may be quoted without explicit permission provided that full credit, including $(\mathcal{C}$ notice, is given to the source. 
Jens Ludwig and Philip J. Cook NBER Working Paper No. 7166

June 1999

JEL No. D8, J17, H51

\section{ABSTRACT}

This paper presents the first attempt to estimate the benefits of reducing crime using the contingent-valuation (CV) method. We focus on gun violence, a crime of growing policy concern in America. Our data come from a national survey in which we ask respondents referendum-type questions that elicit their willingness-to-pay (WTP) to reduce gun violence by 30 percent. We estimate that the public's WTP to reduce gun violence by 30 percent equals $\$ 23.8$ billion, or $\$ 750,000$ per injury. Our estimate implies a statistical value of life ( $\$ 4.05$ to $\$ 6.25$ million) that is quite consistent with those derived from other methods.

Jens Ludwig

Georgetown Public Policy Institute

Georgetown University

$3600 \mathrm{~N}$ St, NW, Suite 200

Washington, DC 20007

ludwigj@gunet.georgetown.edu
Philip J. Cook

Terry Stanford Institute of Public Policy

Box 90245

Duke University

Durham, NC 27708

and NBER

cook@pps.duke.edu 


\section{INTRODUCTION}

In 1996 a total of 14,037 people were killed as the result of gun assaults in the United States, and perhaps another 70,000 or so were non-fatally wounded (CDC, 1999, Cook et al., 1999). Concern about gun violence has prompted a substantial policy response. For example, in New York City, the elite Street Crimes Unit employs aggressive stop-and-search tactics to reduce illegal gun carrying in high-crime neighborhoods (Bratton and Kobler, 1998). In St. Louis the police seek parental consent to search homes and seize illegal firearms kept by teens (Rosenfeld and Decker, 1996), while the Boston Gun Project targets illegal gun trafficking and gang shootings (Kennedy, Piehl and Braga, 1996, Piehl, Kennedy and Braga, 1998). At the national level, policies ranging from background checks for gun-show sales to an outright ban on handguns are being actively considered. ${ }^{1}$

While at least some of these programs may be effective in reducing gun violence (Blumstein and Rosenfeld, 1998), each imposes some cost on society in the form of additional government expenditures and inconvenience to citizens. Identifying the optimal amount of enforcement and regulatory activity to reduce gun violence requires cost-benefit analysis (Becker, 1968, Stigler, 1970, Rottenberg, 1970), which in turn requires estimates for the benefits of reducing gun injuries. Such estimates are also relevant for the lawsuits that a growing number of cities have filed against the gun industry, and for proposals to increase the tax on firearms.

The present paper represents the first attempt to estimate the benefits of reducing crime

1 See Fox Butterfield, "Small-Print Provisions of Gun Bill Please Federal Officials Best," New York Times, May 22, 1999, and "Handguns: Who Will Stand Up?" Editorial, Washington Post, April 28, 1999. 
using the contingent-valuation (CV) method. Our focus on gun violence in particular is motivated by the growing policy concern about this issue. We adopt the standard approach of public economics and define the benefit of a public good as what society is willing to pay (WTP) to achieve some change in the level of the good (Viscusi, 1992). The public good in question here is freedom from the ex ante risk of victimization, with the attendant reduction in fear and self-protection effort. This ex ante approach is appropriate for the decision problem facing policymakers, who must decide whether to fund crime-control programs that reduce future crimes to anonymous victims.

In contrast, previous studies of the benefits of reducing gun violence have adopted an $e x$ post approach that begins with a count of the annual number of gunshot injuries and then multiplies this figure by some estimate of the costs per injury. ${ }^{2}$ The primary limitation with this framework is that it is incomplete, and ignores the costs that the risk of gun violence imposes on even citizens who are not victimized. Much of this research has been conducted within the public health "cost-of-illness" (COI) tradition, which understates the cost per injury by focusing only on the costs of medical treatment for gunshot injuries and other direct costs plus an incomplete measure of lost productivity (Max and Rice, 1993). ${ }^{3}$ More recent studies improve on the COI approach by adding measures for the value of life and health obtained from the

${ }^{2}$ Only a handful of studies have adopted an ex ante approach to evaluating the benefits of reducing crime. All of these studies rely on hedonic-pricing methods to relate crime rates and housing prices (Thaler, 1978, Hellman and Naroff, 1978, Rizzo, 1979). These estimates rely on data from a single city, may confound the price effects of crime with other factors, and are incomplete. None of these studies focuses on gun violence specifically.

${ }^{3}$ The COI approach defines lost productivity as foregone earnings plus the lost value of household work, which ignores all other forms of non-market production. 
workplace-risk or jury-award literatures (Miller and Cohen, 1996, 1997, Miller Cohen and Wiersema, 1996, Anderson, forthcoming), though even these studies still adopt an ex post framework.

The estimates presented in the current paper are obtained from a nationally representative CV survey of 1,204 adults conducted in 1998. The survey elicits respondents' WTP to finance a 30 percent reduction in gun violence using a referendum-type CV question. The advantages of our CV approach are that it yields comprehensive estimates for societal WTP, utilizes nationally representative data, and allows a focus on a specific type of crime that is the subject of considerable public-policy concern.

Our results suggest that a 30 percent reduction in gun violence is worth $\$ 23.8$ billion to the American public. Dividing this figure by the number of gunshot injuries in 1996 implies a WTP per injury equal to around $\$ 750,000$. Despite some limitations of the CV data used to derive our estimates, these figures imply a value for one statistical life that is quite consistent with those derived in other contexts (Viscusi, 1992, 1993).

The paper is organized as follows. The second section reviews the willingness-to-pay approach and discusses the application of this method to the case of gunshot injuries. The third section describes our data and the fourth presents the empirical results. The fifth section discusses the implications of these findings.

\section{THE WILLINGNESS-TO-PAY APPROACH}

In this section we discuss the willingness-to-pay approach within the context of gun violence, and then discuss different methods for estimating WTP. 


\section{A. Defining Willingness-to-Pay}

Under the traditional benefit-cost framework of public economics, the benefits of a violence-reduction program consists of the sum of the values that citizens are willing to pay (WTP) to fund some program or policy that reduces the risk of injury. We assume that individual WTP to support a program to reduce gun violence is motivated by three factors.

First, the individual may attach some value to the reduction in risk of being shot.

Second, she may value the reduction in risk to other members of her household. Because we assume that individuals value the well-being of others in the household and because households pool income, we follow Manning et al. (1991) and treat households as the economic unit of interest.

Finally, she may receive some financial gain from reductions in the number of gunshot injuries to strangers, since some of the relevant costs are shared across members of the community through government programs and private insurance. Further, she may benefit from a general improvement in the quality of life in the community, as a reduced threat of being caught in the cross fire engenders more socializing.

Total social WTP is defined as the sum of what each individual household is willing to pay. As a practical matter, whether financial and other externalities are actually reflected in people's survey responses or market behaviors is not clear. Consumers may have imperfect information about the external costs associated with injuries to others, or may simply not consider these costs. While analysts could in principle directly measure the financial externalities associated with gunshot injuries and add this to the results of a CV survey, the net effect of financial and other externalities is unlikely to be a simple addition of these factors.

\section{B. Measuring WTP}

One way to measure societal WTP for programs that reduce health risks is to examine marketplace behavior. For example, a widely used approach is to examine the extra wage 
compensation that workers require in order to take risky jobs; these wage premiums reflect the price of some health risk in the labor market. ${ }^{4}$ Another possibility is to examine variations in the prices of housing ${ }^{5}$ or other consumer goods ${ }^{6}$ related to health risks to estimate the value that people attach to risk reduction. These measures are in principle incomplete and in practice difficult to implement due to the possibility of unobservables correlated with both prices and risks.

When market behavior cannot be directly examined to estimate societal WTP for a public good, the preferred method, known as "contingent valuation (CV)," is to survey a representative group of respondents about how much they would be willing to pay. A 1992 panel sponsored by the National Oceanic and Atmospheric Administration (NOAA) outlined the key components of a CV study that would maximize the likelihood of producing reliable results (Arrow et al., 1993), which include the use of referendum formats that ask respondents to vote on a hypothetical government program. The referendum format is deemed preferable to open-ended questions because citizens have experience in casting such votes, and because the referendum format minimizes incentives to free ride (Mitchell and Carson, 1989).

Whether even high-quality CV studies produce reliable estimates of WTP remains the topic of ongoing debate. One concern stems from the tendency of survey respondents to present themselves favorably to interviewers (Sudman and Bradburn, 1974), which produces social

\footnotetext{
${ }^{4}$ See for example Smith and Gilbert (1985), Moore and Viscusi (1988a,b, 1990a,b), and Viscusi and Moore (1989).

${ }^{5}$ See for example Gayer, Hamilton and Viscusi (1998).

${ }^{6}$ For a comprehensive review see Viscusi (1993).
} 
desirability bias or yea-saying. A related concern is the possibility that $\mathrm{CV}$ responses are motivated more by the respondent's desire to "purchase moral satisfaction" rather than support the provision of a defined quantity of some public good (Kahneman and Knetsch, 1992). Both problems may manifest themselves in what is known as the "embedding effect," where the respondent's WTP is independent of the quantity of the public good that is being provided.

The empirical evidence on the existence of embedding effects is mixed (see, for example, Desvousges et al., 1993 versus Balson et al., 1990). Other studies provide support for the CV method using experimental designs that compare reported with actual WTP, or by comparing CV responses to estimated travel times to use parks and other public goods or to wage premiums associated with health risks (Brookshire et al., 1982, Viscusi and O’Conner, 1984, Brookshire and Coursey, 1987, Smith, 1992, Hanemann, 1994). Yet the evidence on the CV method is not unequivocal (Hausman, 1993, Diamond and Hausman, 1994).

\section{CONTINGENT VALUATION SURVEY DATA}

The 1998 National Gun Policy Survey (NGPS) is a nationally representative telephone survey of 1,204 American adults conducted during the Fall of 1998 by the National Opinion Research Center (NORC) at the University of Chicago. Interviews were conducted with one adult per sampled household, with the adult chosen randomly via the most-recent-birthday method. The response rate for the NGPS was 61 percent (see Kuby, Imhof and Shin, 1999).

After a series of questions asking about their attitudes towards government and various current or proposed gun regulations, respondents are asked the following questions: "Suppose that you were asked to vote for or against a new program in your state to reduce gun thefts and illegal gun dealers. This program would make it more difficult for criminals and delinquents to 
obtain guns. It would reduce gun injuries by about 30 percent, but taxes would have to be increased to pay for it. If it would cost you an extra [ $\$ 50 / \$ 100 / \$ 200]$ in annual taxes would you vote for or against this new program?" The amount of the tax increase that the respondent is asked about, either $\$ 50, \$ 100$ or $\$ 200$, is randomly determined by the survey software.

Respondents are then asked a follow-up where the dollar amount asked about in the initial referendum question is either doubled or halved, depending on whether the respondent's initial answer was positive or negative, respectively.

As noted earlier, we assume that respondents are reporting on the total dollar value that their household would be willing to pay to fund this program, rather than reporting strictly on the value that they themselves would pay. Our assumption is conservative in that if respondents are in fact reporting on personal rather than household WTP, our estimates will understate total societal WTP to fund the hypothetical reduction in gun crime. ${ }^{7}$

The empirical work presented below provides some support for the credibility of these CV responses. For example, WTP is positively related to household income. We also find that WTP increases with household size; since the reduction in risk the household experiences is related to the number of members, this finding suggests that the responses are not driven entirely by social desirability bias or moral satisfaction.

${ }^{7}$ One implication of this assumption is that our analysis should convert the NGPS sampling weights from person weights into household weights. The NGPS respondent weights calculated by NORC equal one divided by the probability of the household's selection into the sample. The weights are then divided by the adult's probability of selection from within the household, equal to $(1 / \mathrm{A})$ where $\mathrm{A}$ is the number of adults in the home. To convert these into household weights we multiply by (1/A). 


\section{EMPIRICAL RESULTS}

We begin by presenting a non-parametric estimate for WTP to reduce gun violence by 30 percent. This estimate does not impose any assumptions on the population distribution of WTP, and suggests a WTP equal to $\$ 21.2$ billion. We then present a more elaborate set of maximumlikelihood estimates that are derived under alternative assumptions about the distribution of WTP. Our preferred estimates suggest a societal WTP equal to $\$ 23.8$ billion, equal to around $\$ 750,000$ per gunshot injury avoided.

\section{A. Non-parametric Estimates}

Table 1 presents the descriptive statistics from the NGPS data. The proportion of respondents who vote to support the violence-reduction program decreases as the amount required to fund the program increases, ranging from 76 percent at a cost of $\$ 50$ more in annual taxes to 38 percent at a cost of $\$ 400$. Figure 1 provides a graphical representation of the cumulative distribution function implied by these descriptive statistics.

If we integrate under the area shown in Figure 1 and multiply by the total number of households in the U.S. - equal to 99.6 million in 1996 (U.S. Bureau of the Census, 1997) - we obtain an estimated total WTP of $\$ 21.2$ billion to reduce assault-related gunshot injuries by 30 percent. In these calculations we assign a WTP of $\$ 0$ to those respondents who answer no to both the first and follow-up CV questions, under the assumption that each individual's WTP to reduce gunshot injuries must be non-negative. While some people may object to the specific mechanism used to reduce gun injuries, presumably few people would be willing to pay to see more Americans shot, and in any case it is not clear that such preferences should be given standing in benefit-cost analyses. In order to convert this estimate into WTP per gunshot injury 
avoided, we can divide total WTP by the estimated annual incidence of assault-related gunshot woundings $(106,000)^{8}$ multiplied by 30 percent. This suggests WTP per injury equal to $\$ 667,000$.

\section{B. Parametric Estimates}

The non-parametric estimate understates societal WTP because it does not interpolate the underlying distribution between the CV bid values or extrapolate beyond the highest value used in the survey. The non-parametric approach is also limited in that it only uses a fraction of the information available with the CV data. In this section we develop refined estimates that use maximum-likelihood methods to estimate societal WTP under a number of different assumptions.

Our empirical strategy is based on the framework outlined by Cameron and James (1987) and Cameron (1988). Let $\mathrm{Y}_{i}$ equal the (unobserved) WTP value that respondent (i) has in mind when answering the first and second referendum questions in the NGPS. The respondent will answer in the affirmative to the first referendum question $\left(\mathrm{I}_{1 \mathrm{i}}=1\right)$ if the "price" of the program in the form of higher taxes $\left(t_{1 i}\right)$ is not greater than the respondent's WTP $\left(Y_{i} \geq t_{1 i}\right)$. Similarly, the respondent will support the program in the follow-up CV question $\left(I_{2 i}=1\right)$ if the new price $t_{2 i}$ is less than WTP $\left(Y_{i} \geq t_{2 i}\right)$, where $t_{2 i}$ is equal to double $t_{1 i}$ if $I_{1 i}=1$ and half of $t_{1 i}$ if $I_{1 i}=0$. We initially assume that $\mathrm{Y}_{\mathrm{i}}$ is log-normally distributed (equation 1), which constrains WTP to be positive.

${ }^{8}$ The estimate is obtained by adding the 14,037 fatal gunshot assaults in 1996 to the estimated 73,096 non-fatal gun assaults that receive treatment in the ED (Cook et al., 1999). To account for nonfatal gunshot injuries treated outside of the ED we estimate the ratio of nonfatal doctor's office- to ED-treated gunshot injuries (0.19) from the 1995-1996 National Ambulatory Medical Care Survey and the ratio of untreated to ED-treated gunshot injuries (0.07) from the 1987-1994 National Crime Victimization Survey. 
(1)

$$
\log Y_{i}=\beta+u_{i}, \quad u_{i} \sim N\left(0, \sigma^{2}\right)
$$

From this setup we can estimate household WTP using the "interval-data" or "doublebounded" model from Hanemann, Loomis and Kanninen (1991). The probabilities for the four possible joint outcomes for the first $\left(\mathrm{I}_{1 \mathrm{i}}\right)$ and second $\left(\mathrm{I}_{2 \mathrm{i}}\right)$ referendum questions are given in equations (2) through (5). (Recall that $\mathrm{t}_{2 \mathrm{i}}=2 \mathrm{t}_{1 \mathrm{i}}$ if $\mathrm{I}_{1 \mathrm{i}}=1$, and $\mathrm{t}_{2 \mathrm{i}}=0.5 \mathrm{t}_{1 \mathrm{i}}$ if $\mathrm{I}_{1 \mathrm{i}}=0$ ).

$$
\begin{array}{ll}
\mathrm{P}\left[\mathrm{I}_{1 \mathrm{i}}=1, \mathrm{I}_{2 \mathrm{i}}=1\right] & =\mathrm{P}\left[\mathrm{Y}_{\mathrm{i}} \geq \mathrm{t}_{2 \mathrm{i}}>\mathrm{t}_{1 \mathrm{i}}\right]=\mathrm{P}\left[\mathrm{Y}_{\mathrm{i}} \geq \mathrm{t}_{2 \mathrm{i}}\right] \\
& =\mathrm{P}\left[\mathrm{u}_{1 \mathrm{i}} / \sigma \geq\left(\mathrm{t}_{2 \mathrm{i}}-\beta\right) / \sigma\right]=1-\mathrm{F}\left[\left(\mathrm{t}_{2 \mathrm{i}}-\beta\right) / \sigma\right] \\
\mathrm{P}\left[\mathrm{I}_{1 \mathrm{i}}=0, \mathrm{I}_{2 \mathrm{i}}=0\right] \quad & \mathrm{P}\left[\mathrm{Y}_{\mathrm{i}}<\mathrm{t}_{2 \mathrm{i}}<\mathrm{t}_{1 \mathrm{i}}\right]=\mathrm{P}\left[\mathrm{Y}_{\mathrm{i}}<\mathrm{t}_{2 \mathrm{i}}\right] \\
& =\mathrm{P}\left[\mathrm{u}_{1 \mathrm{i}} / \sigma<\left(\mathrm{t}_{2 \mathrm{i}}-\beta\right) / \sigma\right]=\mathrm{F}\left[\left(\mathrm{t}_{2 \mathrm{i}}-\beta\right) / \sigma\right] \\
\mathrm{P}\left[\mathrm{I}_{1 \mathrm{i}}=1, \mathrm{I}_{2 \mathrm{i}}=0\right] \quad & \mathrm{P}\left[\mathrm{t}_{1 \mathrm{i}} \leq \mathrm{Y}_{\mathrm{i}}<\mathrm{t}_{2 \mathrm{i}}\right]=\mathrm{P}\left[\mathrm{Y}_{\mathrm{i}}<\mathrm{t}_{2 \mathrm{i}}\right]-\mathrm{P}\left[\mathrm{Y}_{\mathrm{i}}<\mathrm{t}_{1 \mathrm{i}}\right] \\
& =\mathrm{F}\left[\left(\mathrm{t}_{2 \mathrm{i}}-\beta\right) / \sigma\right]-\mathrm{F}\left[\left(\mathrm{t}_{1 \mathrm{i}}-\beta\right) / \sigma\right] \\
\mathrm{P}\left[\mathrm{I}_{1 \mathrm{i}}=0, \mathrm{I}_{2 \mathrm{i}}=1\right] \quad & \mathrm{P}\left[\mathrm{t}_{2 \mathrm{i}} \leq \mathrm{Y}_{\mathrm{i}}<\mathrm{t}_{1 \mathrm{i}}\right] \quad=\mathrm{P}\left[\mathrm{Y}_{\mathrm{i}}<\mathrm{t}_{1 \mathrm{i}}\right]-\mathrm{P}\left[\mathrm{Y}_{\mathrm{i}}<\mathrm{t}_{2 \mathrm{i}}\right] \\
& =\mathrm{F}\left[\left(\mathrm{t}_{1 \mathrm{i}}-\beta\right) / \sigma\right]-\mathrm{F}\left[\left(\mathrm{t}_{2 \mathrm{i}}-\beta\right) / \sigma\right]
\end{array}
$$

We obtain estimates for the parameters of this model by applying maximum-likelihood estimation (MLE) to the log-likelihood function in equation (6).

$$
\begin{aligned}
\ln L=\sum_{\mathrm{i}} \quad & \left(\mathrm{I}_{1 \mathrm{i}}\right)\left(\mathrm{I}_{2 \mathrm{i}}\right)\left\{1-\mathrm{F}\left[\left(\mathrm{t}_{2 \mathrm{i}}-\beta\right) / \sigma\right]\right\}+ \\
& \left(1-\mathrm{I}_{1 \mathrm{i}}\right)\left(1-\mathrm{I}_{2 \mathrm{i}}\right)\left\{\mathrm{F}\left[\left(\mathrm{t}_{2 \mathrm{i}}-\beta\right) / \sigma\right]\right\}+ \\
& \left(\mathrm{I}_{1 \mathrm{i}}\right)\left(1-\mathrm{I}_{2 \mathrm{i}}\right)\left\{\mathrm{F}\left[\left(\mathrm{t}_{2 \mathrm{i}}-\beta\right) / \sigma\right]-\mathrm{F}\left[\left(\mathrm{t}_{1 \mathrm{i}}-\beta\right) / \sigma\right]\right\}+ \\
& \left(1-\mathrm{I}_{1 \mathrm{i}}\right)\left(\mathrm{I}_{2 \mathrm{i}}\right)\left\{\mathrm{F}\left[\left(\mathrm{t}_{1 \mathrm{i}}-\beta\right) / \sigma\right]-\mathrm{F}\left[\left(\mathrm{t}_{2 \mathrm{i}}-\beta\right) / \sigma\right]\right\}
\end{aligned}
$$

The coefficient estimate for the variables $t_{1 i}$ and $t_{2 i}$ is an estimate for $1 / \sigma$, which in turn allows us to identify an estimate $b$ for the parameter $\beta$. Calculating the standard errors for mean and median household WTP is complicated by the fact that our estimate for $\mathrm{b}$ is really the ratio of 
two estimates - the estimated value for $\beta / \sigma$ divided by an estimate for $1 / \sigma$. Our method for calculating standard errors is provided in the technical appendix. If $\mathrm{w}_{\mathrm{i}}$ represents the NGPS sampling weight for household (i), which equals the number of households in the population that each sampled household represents, then estimated societal WTP is given by equation (7). While b provides an unbiased estimate for the expected value of $\log$ WTP, for a log-normal variable the mean of WTP itself will be given by $\exp (b) \times \exp \left(0.5 \sigma^{2}\right)$ as in equation (7) (Manning, 1998).

Societal WTP $=\sum_{i} \mathrm{w}_{\mathrm{i}} \times \exp (\mathrm{b}) \times \exp \left(0.5 \sigma^{2}\right)$

In Figure 2, we compare the cumulative distribution function for WTP implied by the parametric estimates presented in Table 3 with the non-parametric function from Figure 1. The MLE estimates imply mean and median household WTP equal to $\$ 203$ and aggregate WTP equal to $\$ 20.2$ billion, or $\$ 635,000$ per injury (Table 4 ). The parametric estimate does not exceed the non-parametric figure as might be expected because the former uses data from both the first and second $\mathrm{CV}$ questions, while the latter is based largely on responses to the first CV question.

We further refine our parametric estimates by calculating mean household WTP conditional on a vector of household characteristics $\mathbf{X}_{\mathrm{i}}$ that may affect the risk of gunshot injury, attitudes towards risk, or ability to pay. In our empirical analysis the vector of household variables includes income, household composition (the number of children under 6 or 6 to 17 , and the number of adults), household gun ownership, and race. ${ }^{9}$

As seen in Table 3, the coefficient estimates for these covariates provides some evidence

${ }^{9}$ Since only 2.2 percent of all marriages were inter-racial in 1992, the last year for which such data are available (U.S. Bureau of the Census, 1999), we infer "household race" from the respondent's race. 
on the credibility of our WTP responses. Income has a strong positive effect on support for the violence program. We also find that households with guns have lower WTP than other households to support gun-violence reduction, consistent with previous findings that gun owners are less supportive of gun control than non-owners (Teret et al., 1998). Table 3 also provides some support for the assumption that respondents are reporting on household (rather than individual) WTP, since WTP has a strong correlation with the number of children in the home.

Including the household covariates serves to increase our estimated mean WTP per household from $\$ 203$ to $\$ 239$ (Table 4). Total WTP to reduce gun violence by 30 percent equals $\$ 23.8$ billion, or $\$ 748,000$ per injury. We use household-level covariates because we interpret the CV responses as reflections of household (rather than individual) WTP. If different individuals within the home would report different WTP values, then our estimates should still be unbiased (since adults are randomly selected from households) but may be inefficient. ${ }^{10}$

\section{Sensitivity Analyses}

We find that our estimates are fairly robust to assumptions about the distribution of WTP. Re-estimating equation (7) with covariates under the assumption that WTP has a log-logistic (rather than log-normal) distribution produces an estimated mean WTP of \$206. Using a normal distribution, which allows WTP to be negative, produces an estimate of $\$ 213$.

One concern with these $\mathrm{CV}$ data is the possibility that responses to the follow-up CV

${ }^{10}$ To explore this possibility, we re-estimated our preferred MLE model after restricting the sample to married respondents and including an indicator for the respondent's gender. While the coefficient estimate for an indicator variable for husbands is negative and statistically significant, inclusion of this variable serves to reduce estimated mean WTP by less than 7 percent. 
question are influenced by the initial question. As Cameron and Quiggin (1994) note, respondents may become more certain about their response to the second rather than first question because they have had more time to reflect on the public good in question. Alternatively, respondents may believe that the first question provides information about the actual average cost of the public good, and may then react negatively to the second question that asks the respondent to pay "more than it costs." The descriptive statistics presented in Table 1 provides some evidence to support this second effect. For example, Table 1 shows that 69 percent of respondents who are asked about a $\$ 100$ tax increase in the first question will pay this much to support the program, though only 51 percent of those who are asked about a $\$ 50$ increase in the first question will support a $\$ 100$ tax increase ( 76 percent $\times 67$ percent).

To address the possibility that the respondent is sensitized by the first CV question, and thus that the first and second questions produce draws from slightly different WTP distributions, we follow Cameron and Quiggin (1994) and re-estimate WTP using a bivariate probit model. The bivariate probit model allows for different means for the first and second WTP values $\left(\boldsymbol{\beta}_{1} \neq \boldsymbol{\beta}_{2}\right)$, as well as separate error processes that have different variances $\left(\sigma_{1}{ }^{2} \neq \sigma_{2}{ }^{2}\right)$ and are only imperfectly correlated $\left(\operatorname{Corr}\left[\mathrm{u}_{1 \mathrm{i}}, \mathrm{u}_{2 \mathrm{i}}\right]=\rho<1\right)$. While the bivariate probit model affords greater flexibility than the MLE model given by equation (6), this strategy comes at the cost of less precise estimates (Alberini, 1995) and makes interpretation of the results somewhat complicated. Our bivariate probit estimates suggest a mean WTP of $\$ 309$ for the first referendum question and $\$ 209$ for the second. If responses to the first CV question are more accurate, then the estimates presented in Table 4 may somewhat understate societal WTP.

Another concern that commonly arises with CV studies is that of "protest zeroes," defined $-13-$ 
as cases in which the respondent rejects the hypothetical market scenario even though her true WTP exceeds the stated "price" of the referendum (Mitchell and Carson, 1989). The proper definition of protest zeroes is complicated in our application. Fairly uncontroversial is the case of tax protestors - those respondents who object to financing the program out of tax revenues, but who would be willing to pay the stated amount to achieve a 30 percent reduction in gun violence if the program were financed by some other means. One possibility is to identify as tax protesters the 24 percent of respondents who "strongly agree" with the survey question that "taxes are too high." When we re-estimate our model without these respondents in the sample which is the preferred method for dealing with protesters (Freeman, 1993) - our estimate is only 13 percent higher than the $\$ 239$ figure reported in Table 4 .

More complicated are cases where the respondent objects to the mechanism for reducing gun violence, rather than the mechanism for financing the program. The NGPS asks about programs that target the illegal use or transmission of firearms, which in turn should reduce gun violence holding the overall crime rate constant. Respondents who object to these interventions should only be counted as protest zeroes if alternative interventions exist that could plausibly reduce gun crime without reducing the overall crime rate, which is a debatable proposition. In any case, we classify as intervention-protesters those who "strongly disagree" that "the government should do everything it can to keep handguns out of the hands of criminals, even if it means that it will be harder for law-abiding citizens to purchase handguns." Excluding these respondents produces only a 7 percent increase in WTP compared with Table 4 .

\section{DISCUSSION}

This paper presents the first attempt to estimate the demand for reductions in crime using 
contingent-valuation (CV) methods. Our estimates suggest that a 30 percent reduction in gun violence is worth $\$ 23.8$ billion to the American public in 1998 dollars, around $\$ 750,000$ per injury. These findings are generally quite robust to our decisions about the estimation procedure - even the descriptive statistics imply a societal WTP of $\$ 21.2$ billion.

The most fundamental issue is whether the NGPS survey responses reflect respondents' preferences about a given quantity of violence reduction rather than social desirability bias, moral satisfaction or some other motivation. CV responses that are motivated by something other than the public's demand for a public good may be insensitive to the quantity of the public good that is offered (the embedding effect), and thus not useful for benefit-cost analysis.

Our crude test for an embedding effect with the NGPS data suggests that WTP is in fact sensitive to the amount of risk reduction provided. Table 4 shows that WTP increases with the number of children in the home, which in turn is related to the total amount of risk reduction that the household gains from a violence-reduction program. Since these findings could be explained by taste or other differences between households with and without children, we re-estimated our models using only those households with children. We find that each additional child in the home under the age of 6 increases the respondent's WTP by 50 percent, and each additional child between 6 and 17 increases WTP by 25 percent. While these findings provide some evidence against an embedding effect, for some reason additional adults within the home do not appear to increase household WTP.

Our estimates are based on CV questions that are limited in length and level of detail by the constraints of telephone survey methods, and are thus necessarily imperfect. The CV questions used in the gun survey described here can be criticized for excluding important 
information about the hypothetical interventions that respondents are asked to support, a problem that plagues all CV studies to some degree. The NGPS questions do not specify the change in risk to the respondent, although there is substantial heterogeneity in the risk of gunshot injury within the population and a 30 percent reduction in gun injuries will imply somewhat different changes for respondents according to their community's baseline risks. A related concern is that the questions do not specify where the interventions will be targeted, and thus who will benefit from the program. For example, what society will pay to reduce gun injuries to downtown office workers may be different from what society will pay to reduce the number of gang shootings.

Despite the limitations of these CV survey data, our estimates for society's WTP to reduce gun violence are remarkably consistent with previous estimates from wage-risk tradeoffs. Deriving a value of statistical life from our $\mathrm{CV}$ results is complicated somewhat by the fact that our question reflects WTP for both fatal and nonfatal gunshot injuries. If we start with the extreme assumption that WTP is driven entirely by concern about fatal gunshot injuries, then since we have shown that around 12 percent of assault-related gunshot injuries are fatal, our preferred estimate of $\$ 750,000$ per gunshot injury avoided implies a value per statistical life equal to $\$ 6.25$ million. But presumably part of WTP to reduce gun injuries is motivated by concern about non-fatal gunshot injuries. If we assume that non-fatal gunshot injuries are twice as undesirable as the average workplace injury, our estimates imply a value per statistical life of $\$ 4.05$ million. ${ }^{11}$ By way of comparison, studies of wage-risk tradeoffs produce estimates for the

${ }^{11}$ This comes from multiplying twice the highest estimate for workplace injuries reported in Viscusi (1993), around $\$ 300,000$ in 1998 dollars, by the number of nonfatal gun injuries for every fatality (7.33), and subtracting this figure ( $\$ 2.2$ million) from the estimated value of 8.33 gun injuries ( $\$ 6.25$ million). 
value of life (also in 1998 dollars) between $\$ 3.7$ and $\$ 8.6$ million (Viscusi, 1993).

We would expect societal WTP to be far smaller if citizens were concerned only about reducing the risk of gun injury to themselves and members of their families. The reason is that gunshot injuries in the U.S. are highly concentrated among a group of people who on average are far less risk averse than are members of the general population. Two-thirds of all firearm homicides in 1996 were to males between the ages of 15 and 39 (CDC, 1999), and three-quarters of gun homicide victims under 21 in Boston in 1990-1994 had criminal records (Kennedy, Piehl and Braga, 1996). Levitt and Venkatesh (1998) studied the records documenting the opportunities and violence-victimization risks for members of a crack-dealing street gang: Comparing the risk to the reward suggests that they placed a value on a statistical life of just $\$ 55,000$ on average. Our WTP estimates thus suggest that the benefits from reducing gun violence in America are substantial, and accrue primarily to citizens at low personal risk of injury through reductions in risk to others in the home, lower tax bills, or improvements to the overall quality of community life. 


\section{REFERENCES}

Alberini, Anna. (1995) "Efficiency vs Bias of Willingness-to-Pay Estimates: Bivariate and Interval-Data Models." Journal of Environmental Economics and Management. 29: 169-180.

Anderson, David A. (Forthcoming) "The Aggregate Burden of Crime." Journal of Law and Economics.

Arrow, Kenneth et al (1993) "Report of the NOAA Panel on Contingent Valuation." Federal Register. Washington, DC, January 15, 1993.

Balson, W.E. et al (1990) "Development and Design of a Contingent Valuation Survey for Measuring the Public's Value for Visibility Improvements at the Grand Canyon National Park." Working Paper.

Becker, Gary. (1968) "Crime and Punishment: An Economic Approach." Journal of Political Economy. 76(2): 169-217.

Blumstein, Alfred and Richard Rosenfeld (1998) "Explaining Recent Trends in U.S. Homicide Rates." Journal of Criminal Law and Criminology. 88(4): 1175-1216.

Bratton, William and Peter Knobler (1998) Turnaround: How America's Top Cop Reversed the Crime Epidemic. New York: Random House.

Brookshire, David S. and Don L. Coursey (1987) "Measuring the Value of a Public Good: An Empirical Comparison of Elicitation Procedures." American Economic Review. 77(4): 554-566.

Brookshire, David S., Mark A. Thayer, William D. Schulze, and Ralph C. d'Arge. (1982) "Valuing Public Goods: A Comparison of Survey and Hedonic Approaches." American Economic Review. 72(1): 165-177.

Cameron, Trudy Ann (1988) "A New Paradigm for Valuing Non-Market Goods Using Referendum Data: Maximum Likelihood Estimation by Censored Logistic Regression." Journal of Environmental Economics and Management. 15: 355-379.

Cameron, Trudy Ann and Michelle D. James (1987) "Efficient Estimation Methods for 'Closed Ended' Contingent Valuation Surveys." Review of Economics and Statistics. 69: 269-276.

Cameron, Trudy Ann and John Quiggin (1994) "Estimation Using Contingent Valuation Data from a 'Dichotomous Choice with Follow-Up' Questionnaire." Journal of Environmental Economics and Management. 27: 218-234.

Centers for Disease Control (1999) Downloaded from <<www.cdc.gov/ncipc >> May 25, 1999. 
Cook, Philip J., Bruce Lawrence, Jens Ludwig and Ted R. Miller (1999) "The Medical Costs of Gunshot Injuries in the United States." Working Paper, Duke University.

Desvousges, William H. et al. (1993) "Measuring Natural Resource Damages with Contingent Valuation: Tests of Validity and Reliability." In Contingent Valuation: A Critical Assessment. Jerry A. Hausman (Ed.) Amsterdam: North Holland. pp. 91-164.

Diamond, Peter A. and Jerry A. Hausman (1994) "Contingent Valuation: Is Some Number Better than No Number?" Journal of Economic Perspectives. 8(4): 45-64.

Freeman, Myrick A. (1993) The Measurement of Environmental and Resource Values: Theory and Methods. Washington, DC: Resources for the Future.

Gayer, Ted, James T. Hamilton, and W. Kip Viscusi. (1998) "Private Values of Risk Tradeoffs at Superfund Sites: Housing market Evidence on Learning about Risk." Working Paper, Georgetown University.

Hanemann, Michael (1994) "Valuing the Environment Through Contingent Valuation." Journal of Economic Perspectives. 8(4): 19-43.

Hanemann, Michael, John Loomis and Barbara Kanninen (1991) "Statistical Efficiency of Double-Bounded Dichotomous Choice Contingent Valuation." American Journal of Agricultural Economics. 1255-1263.

Hausman, Jerry A. (1993) Contingent Valuation: A Critical Assessment. Amsterdam: North Holland.

Hellman, Daryl A. and Joel L. Naroff (1979) "The Impact of Crime on Urban Residential Property Values." Urban Studies. 16: 105-112.

Kahneman, Daniel and Jack L. Knetsch (1992) "Valuing Public Goods: The Purchase of Moral Satisfaction." Journal of Environmental Economics and Management. 22: 57-70.

Kennedy, David M., Anne M. Piehl, and Anthony A. Braga (1996) "Youth Violence in Boston: Gun Markets, Serious Youth Offenders and a Use-Reduction Strategy." Law and Contemporary Problems. 59(1): 147-196.

Kuby, Alma M., Laurie Imhof, and Hee-Choon Shin. (1999) Fall 1998 National Gun Policy Survey: Methodology Report. Chicago: National Opinion Research Center.

Levitt, Steven D. and Sudhir Alladi Venkatesh (1998) "An Economic Analysis of a Drug-Selling Gang's Finances." University of Chicago Working Paper. 
Maddala, G.S. (1977) Econometrics. New York: McGraw-Hill.

Manning, Willard G., Emmett B. Keeler, Joseph P. Newhouse, Elizabeth M. Sloss, and Jeffrey Wasserman (1991) The Costs of Poor Health Habits. Cambridge, MA: Harvard.

Manning, Willard G. (1998) "The Logged Dependent Variable, Heteroscedasticity, and the Retransformation Problem." Journal of Health Economics. 17: 283-295.

Max, Wendy and Dorothy P. Rice. (1993) "Shooting In the Dark: Estimating the Cost of Firearm Injuries." Health Affairs. 171-185.

Miller, Ted R. and Mark A. Cohen. (1996) "Chapter 5: Costs." In The Textbook of Penetrating Trauma. Rao R. Ivatury and C. Gene Cayten (Eds.) Baltimore: Williams \& Wilkins.

Miller, Ted R. and Mark A. Cohen (1997) "Costs of Gunshot and Cut/Stab Wounds in the United States, With Some Canadian Comparisons." Accident Analysis and Prevention. 29(3): 329-341.

Miller, Ted R., Mark A. Cohen, and Brian Wiersema (1996) Victim Costs and Consequences: A New Look. NCJ 155282. Washington, DC: NIJ.

Mitchell, Robert Cameron and Richard T. Carson (1989) Using Surveys to Value Public Goods: The Contingent Valuation Method. Washington, DC: Resources for the Future.

Moore, Michael J. and W. Kip Viscusi (1988a) "Doubling the Estimated Value of Life: Results Using New Occupational Fatality Data." Journal of Policy Analysis and Management. 7(3): 476490.

Moore, Michael J. and W. Kip Viscusi (1988b) "The Quantity-Adjusted Value of Life." Economic Inquiry. 26(3): 369-388.

Moore, Michael J. and W. Kip Viscusi (1990a) "Discounting Environmental Health Risks: New Evidence and Policy Implications." Journal of Environmental Economics and Management. 18(2): S51-S62.

Moore, Michael J. and W. Kip Viscusi (1990b) "Models for Estimating Discount Rates for LongTerm Health Risks Using Labor Market Data." Journal of Risk and Uncertainty. 3(4): 381-402.

Piehl, Anne M., David M. Kennedy and Anthony A. Braga (1998) "Problem Solving and Youth Violence: An Evaluation of the Boston Gun Project." Working paper, Harvard University.

Rizzo, Mario J. (1979) "The Costs of Crime to Victims: An Empirical Analysis." Journal of Legal Studies. 8: 177-205. 
Rosenfeld, Richard and Scott H. Decker (1996) "Consent to Search and Seize: Evaluating an Innovative Youth Firearm Suppression Program." Law and Contemporary Problems. 59(1): 197-220.

Rottenberg, Simon (1970) "The Social Cost of Crime and Crime Prevention." In Barbara McLennan (Ed.) Crime in Urban Society. Cambridge, MA: University Press. pp. 43-60.

Smith, V. Kerry (1992) "Arbitrary Values, Good Causes, and Premature Verdicts." Journal of Environmental Economics and Management. 22: 71-89.

Stigler, George J. (1970) "The Optimum Enforcement of Laws." Journal of Political Economy. 78: 526-536.

Sudman, Seymour and Norman Bradburn (1974) Response Effects In Surveys: A Review and Synthesis. Chicago: Aldine.

Teret, Stephen P., Daniel W. Webster, Jon S. Vernick et al. (1998) "Support for New Policies to Regulate Firearms: Results of Two National Surveys." New England Journal of Medicine. 339(12): 813-818.

Thaler, Richard (1978) "A Note on the Value of Crime Control: Evidence from the Property Market." Journal of Urban Economics. 5: 137-145.

U.S. Bureau of the Census (1997) Statistical Abstract of the United States: $1997\left(117^{\text {th }}\right.$ Ed.) Washington, DC: GPO.

U.S. Bureau of the Census (1999) <<http://www.census.gov/population/socdemo $>>$ (downloaded on February 22, 1999).

Viscusi, W. Kip. (1992) Fatal Tradeoffs: Public and Private Responsibilities for Risk. New York: Oxford University Press.

Viscusi, W. Kip (1993) "The Value of Risks to Life and Health." Journal of Economic Literature. 31(4): 1912-1946.

Viscusi, W. Kip and Charles O'Connor (1984) "Adaptive Responses to Chemical Labeling: Are Workers Bayesian Decision Makers?" American Economic Review. 74(5): 942-956.

Viscusi, W. Kip and Michael J. Moore (1989) "Rates of Time Preference and Valuations of the Duration of Life." Journal of Public Economics. 38: 297-317.

Yates, F. (1981) Sampling Methods for Censuses and Surveys, $4^{\text {th }}$ Edition Revised and Enlarged. London: Charles Giffin \& Co. 
Table 1

Descriptive Statistics

from the 1998 National Gun Policy Survey

\begin{tabular}{|l|l|l|l|}
\hline & $\begin{array}{l}\text { How vote on } \\
\text { program to reduce } \\
\text { gunshot injuries by } \\
30 \% \text { but cost } \$ 50 \\
\text { more per year in } \\
\text { income taxes? }\end{array}$ & $\begin{array}{l}\text { How vote on } \\
\text { program to reduce } \\
\text { gunshot injuries by } \\
30 \% \text { but cost } \$ 100 \\
\text { more per year in } \\
\text { income taxes? }\end{array}$ & $\begin{array}{l}\text { How vote on } \\
\text { program to reduce } \\
\text { gunshot injuries by } \\
30 \% \text { but cost } \$ 200 \\
\text { more per year in } \\
\text { income taxes? }\end{array}$ \\
\hline $\begin{array}{l}\text { \% vote in favor of } \\
\text { program (N) }\end{array}$ & $75.8(400)$ & $68.5(400)$ & $63.6(404)$ \\
\hline $\begin{array}{l}\text { \% vote in favor of } \\
\text { program on follow- } \\
\text { up Q (N) }\end{array}$ & & $24.2(112)$ & \\
$\begin{array}{l}\text { Amount asked about } \\
\text { on follow-up Q: } \\
\begin{array}{l}\$ 25 \\
\$ 50\end{array}\end{array}$ & $23.3(95)$ & $59.4(268)$ & \\
$\begin{array}{l}\$ 100 \\
\$ 200\end{array}$ & $67.2(290)$ & & \\
$\$ 400$ & & & \\
\hline
\end{tabular}

Source: Authors' calculations from 1998 NGPS; descriptive statistics are calculated using the 1998 NGPS sampling weights. Figures are in 1998 dollars. 
Table 2

Nonparametric Estimates for Mean WTP from NGPS

\begin{tabular}{|l|l|}
\hline Frequency distribution of maximum WTP to & \\
reduce gun assaults by $30 \%$ implied by & \\
descriptive statistics in Table 1 & (\% households) \\
$\$ 0$ & 18.6 \\
25 & 5.6 \\
50 & 7.3 \\
100 & 4.9 \\
200 & 25.8 \\
400 & 37.8 \\
\hline Implied mean WTP per household & $\$ 212.7$ \\
\hline Implied aggregate WTPa & $\$ 21.2$ billion \\
\hline
\end{tabular}

NOTES: Estimates calculated from (weighted) descriptive statistics for NGPS shown in Table 1. Results reported in 1998 dollars. a. Obtained by multiplying mean WTP per household by number of households in U.S. in 1996, which is equal to 99.6 million (U.S. Bureau of the Census, 1997). 
Table 3

Coefficient Estimates from MLE Estimates, from NGPS Contingent Valuation Referendum Data

\begin{tabular}{|l|l|l|}
\hline Variable & Without household covariates & With household covariates \\
\hline Intercept & $3.078(0.155)^{* *}$ & $3.096(0.220)^{* *}$ \\
Bid value $(1 / \sigma)$ & $0.600(0.030)^{* *}$ & $0.634(0.033)^{* *}$ \\
Race & & \\
African-American & & $-0.046(0.131)$ \\
Hispanic & & $-0.129(0.155)$ \\
Other Race & & $-0.213(0.213)$ \\
Region & & \\
\hline Northeast & & $0.057(0.119)$ \\
Midwest & & $-0.156(0.100)$ \\
West & & $-0.155(0.116)$ \\
HH composition & & \\
\hline \# children $<6$ in HH & & $0.229(0.064)^{* *}$ \\
\# children 6-17 in HH & & $0.115(0.041)^{* *}$ \\
\# adults in HH & & $-0.027(0.057)$ \\
Family Income & & \\
\hline \$20-39,999 & & $0.214(0.121)^{*}$ \\
\$40-59,999 & & $0.438(0.135)^{* *}$ \\
\$60,000 plus & & $0.449(0.133)^{* *}$ \\
Income missing & & $0.081(0.141)$ \\
Gun in home & & $-0.201(0.088)^{* *}$ \\
\hline N & & 1,110 \\
Log likelihood & & -759.3 \\
\hline
\end{tabular}

NOTES: Author calculations from applying maximum likelihood estimation to equation (3) for the 1997 gun survey data and equation (11) for the 1998 gun survey data, under the assumption that WTP is normally distributed. ${ }^{* *}=$ Statistically significant at the 5 percent level. ${ }^{*}=$ Statistically significant at the 10 percent level. Figures are in 1998 dollars. 
Table 4

Maximum Likelihood Estimates for WTP to Reduce Gun Assaults by 30\%, from NGPS Data

\begin{tabular}{|l|l|l|}
\hline & Without covariates & With covariates $^{\mathrm{b}}$ \\
\hline $\begin{array}{l}\text { Estimated Willingness-to-pay to reduce } \\
\text { GSW by 30\% }\end{array}$ & & \\
$\begin{array}{l}\text { Mean } \\
(95 \% \text { confidence interval) }\end{array}$ & $\begin{array}{l}\$ 203 \\
(185-220)\end{array}$ & $\begin{array}{l}\$ 239 \\
(103-375)\end{array}$ \\
$\begin{array}{l}\text { Median } \\
(95 \% \text { confidence interval) }\end{array}$ & $\begin{array}{l}\$ 203 \\
(185-220)\end{array}$ & $\begin{array}{l}\$ 204 \\
(68-340)\end{array}$ \\
\hline $\begin{array}{l}\text { Estimated societal WTP for program to } \\
\text { reduce gun assaults by 30\% }\end{array}$ & $\$ 20.2$ billion & $\$ 23.8$ billion \\
\hline $\begin{array}{l}\text { Estimated societal WTP for each gun } \\
\text { assault avoided }\end{array}$ & $\$ 635,000$ & $\$ 748,000$ \\
\hline
\end{tabular}

NOTES: Figures are in 1998 dollars. a. Obtained by multiplying mean WTP per household by number of households in U.S. in 1996, which is equal to 99.6 million (U.S. Bureau of the Census, 1997). b. Covariates included in model are household income, household composition (the number of children under 6 or 6 to 17, and the number of adults), household gun ownership status, and race. 


\section{Technical Appendix \\ Calculating Standard Errors for Mean and Median WTP}

The usual standard error formula for a linear predictor evaluated at some value of the regressors $\mathbf{x}_{\mathbf{0}}$ is given by equation (A1).

$$
\text { (A1) } \quad \operatorname{SE}\left(\mathbf{x}_{0}{ }^{\prime} \mathbf{b}\right)=\left(\mathbf{x}_{0} \mathbf{V} \mathbf{x}_{0}{ }^{\prime}\right)^{1 / 2}
$$

Estimation of the log likelihood given in equation (7) is simplified somewhat because $b$ is a scalar rather than a vector, so $\mathrm{V}$ is also a scalar equal to the variance of $\mathrm{b}, \mathrm{x}_{0}=1$, and equation (A1) simplifies to (A2).
(A2)
$\mathrm{SE}(\mathrm{b})=$
$(\mathrm{V})^{1 / 2}$

The complication in our case comes from the fact that $b$ is actually the ratio of two estimates $b^{\prime} / s^{\prime}$, where $b^{\prime}$ is an estimate for $(\beta / \sigma)$ and $s^{\prime}$ is an estimate for $(1 / \sigma)$. In this case the variance for $b=b^{\prime} / s^{\prime}$ can be approximated by the formula given in equation (A3) (Yates, 1981, p. 190).

(A3) $\quad \mathrm{V}=\operatorname{Var}(\mathrm{b})=\operatorname{Var}\left(\mathrm{b}^{\prime} / \mathrm{s}^{\prime}\right) \approx\left(\mathrm{b}^{\prime} / \mathrm{s}^{\prime}\right)^{2}\left[\left(\operatorname{Var}\left(\mathrm{b}^{\prime}\right)\right) /\left(\mathrm{b}^{\prime}\right)^{2}+\left(\operatorname{Var}\left(\mathrm{s}^{\prime}\right)\right) /\left(\mathrm{s}^{\prime}\right)^{2}\right]$

The final complication is that (A3) gives us the variance for the estimated mean of the natural $\log$ of $\mathrm{Y}$ (WTP), while ultimately we are interested in the variance of predicted mean of the untransformed WTP. With $E[\ln Y]=b$ and $\operatorname{Var}(E[\ln Y])=V$ then the variance of $E[Y]$ is given by equation (A4) (Maddala, 1977, p. 33).

(A4) $\operatorname{Var}(E[Y])=\exp (2 b+V) *\left(e^{V}-1\right)$ 


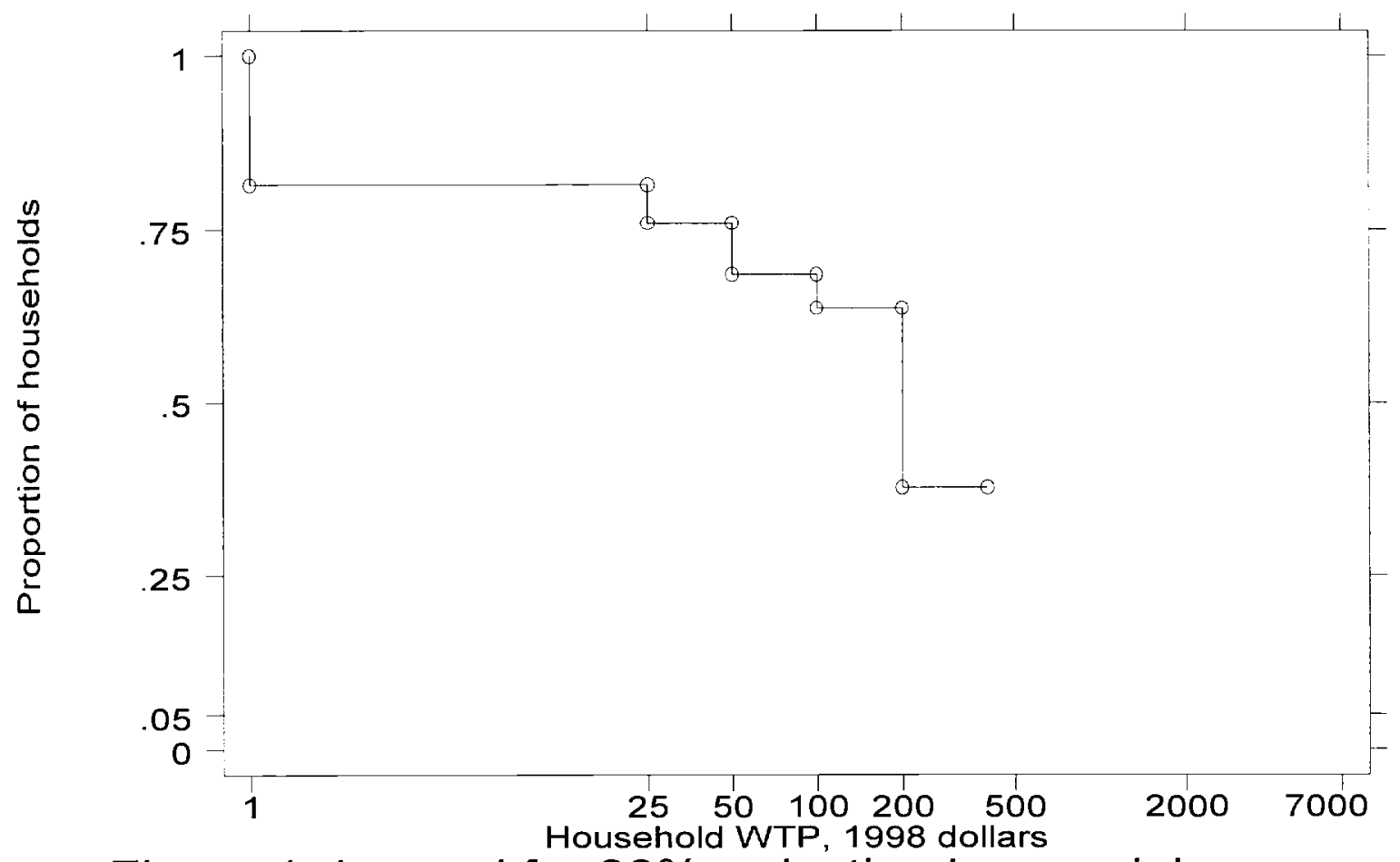

Figure 1 demand for $30 \%$ reduction in gun violence 


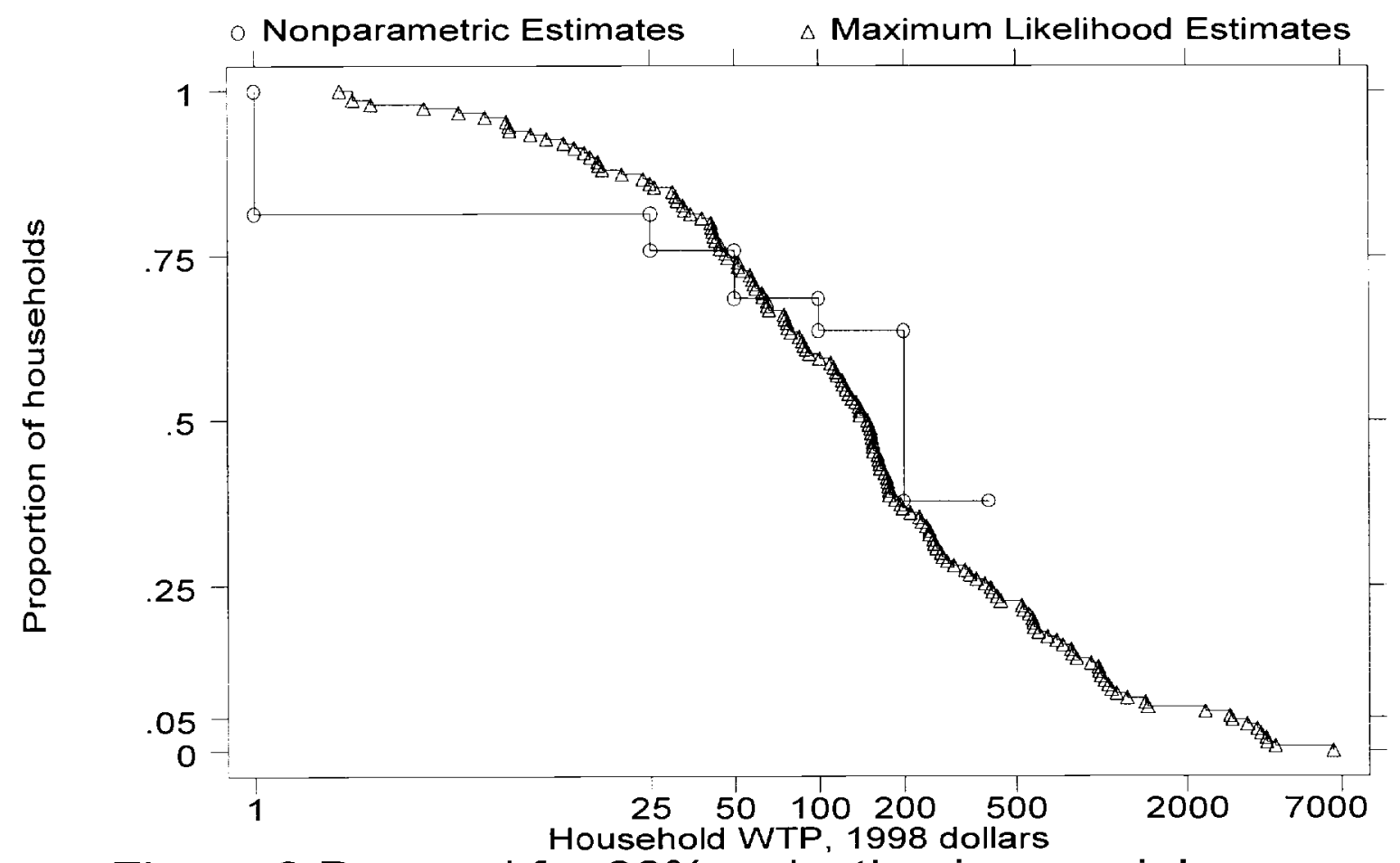

Figure 2 Demand for $30 \%$ reduction in gun violence 